Check for updates

Cite this: RSC Adv., 2018, 8, 1899

Received 15th November 2017 Accepted 27th December 2017

DOI: $10.1039 / c 7 r a 12444 a$

rsc.li/rsc-advances

\section{The improvement of photocatalytic activity of monolayer $\mathrm{g}-\mathrm{C}_{3} \mathrm{~N}_{4}$ via surface charge transfer doping}

\author{
F. L. Yang, $\dagger^{a}$ F. F. Xia, (D) $\dagger^{\star a}$ J. Hu, ${ }^{a}$ C. Z. Zheng, ${ }^{a}$ J. H. Sun (D) *a and H. B. Yi (D) ${ }^{* b}$
}

Graphite-like carbon nitride $\left(\mathrm{g}-\mathrm{C}_{3} \mathrm{~N}_{4}\right)$ has attracted much attention due to its peculiar photocatalytic performance as a visible-light-responsive photocatalyst. However, its insufficient sunlight absorption is not conducive to the photocatalytic activity of the $\mathrm{g}-\mathrm{C}_{3} \mathrm{~N}_{4}$. Herein, by using first-principles density functional theory (DFT) calculations, we demonstrated a simple yet efficient way to achieve improvement of photocatalytic activity of monolayer $\mathrm{g}-\mathrm{C}_{3} \mathrm{~N}_{4}$ via surface charge transfer doping (SCTD) using the electron-drawing tetracyanoquinodimethane (TCNQ) and electron-donating tetrathiafulvalene (TTF) as surface dopants. Our calculations revealed that the electronic properties of monolayer $\mathrm{g}-\mathrm{C}_{3} \mathrm{~N}_{4}$ can be affected by surface modification with TCNQ and TTF. These dopants are capable of drawing/ donating electrons from/to monolayer $\mathrm{g}-\mathrm{C}_{3} \mathrm{~N}_{4}$, leading to the accumulation of holes/electrons injected into the monolayer $\mathrm{g}-\mathrm{C}_{3} \mathrm{~N}_{4}$. Correspondingly, the Fermi levels of monolayer $\mathrm{g}-\mathrm{C}_{3} \mathrm{~N}_{4}$ were shifted towards the valence/conduction band regions after surface modifications with TCNQ and TTF, along with the increase/decrease of work functions. Moreover, the optical property calculations demonstrated that the TCNQ and TTF modifications could significantly broaden the optical absorption of monolayer $\mathrm{g}-\mathrm{C}_{3} \mathrm{~N}_{4}$ in the visible-light regions, yielding an improvement in the photocatalytic activity of monolayer $\mathrm{g}-\mathrm{C}_{3} \mathrm{~N}_{4}$. Our results unveil that SCTD is an effective way to tune the electronic and optical properties of monolayer $\mathrm{g}-\mathrm{C}_{3} \mathrm{~N}_{4}$, thus improving its photocatalytic activity and broadening its applications in splitting water and degrading environmental pollutants under sunlight irradiation.

\section{Introduction}

Graphitic carbonic nitride $\left(\mathrm{g}-\mathrm{C}_{3} \mathrm{~N}_{4}\right)$ has attracted much attention since it was first developed to be a visible-light-driven photocatalyst by Wang and co-workers in 2009 due to its abundance, high stability, and excellent capacity for solar utilization. ${ }^{1}$ Therefore $\mathrm{g}-\mathrm{C}_{3} \mathrm{~N}_{4}$ has been found to be important in applications in diverse fields, ${ }^{1-11}$ including water splitting, ${ }^{1,2}$ $\mathrm{CO}_{2}$ reduction, ${ }^{3,4}$ contaminant degradation, ${ }^{5,6}$ and so on. Unfortunately, bulk $\mathrm{g}-\mathrm{C}_{3} \mathrm{~N}_{4}$ is a medium band gap semiconductor with visible light response (up to $450 \mathrm{~nm}$ ), but low carrier mobility and insufficient sunlight absorption limit its photocatalytic activity, ${ }^{1,8-11}$ which cannot meet the prerequisites of high activity in photocatalytic reaction (both strong light absorption and suitable redox potential). ${ }^{12,13}$ Therefore, there are many reports on the improvement of photocatalytic activity for pristine g- $\mathrm{C}_{3} \mathrm{~N}_{4} \cdot{ }^{14-32}$ For instance, Ma et al. proposed an

\footnotetext{
${ }^{a}$ School of Chemical and Environmental Engineering, Jiangsu University of Technology, Changzhou 213001, Jiangsu, P. R. China

${ }^{b}$ State Key Laboratory of Chemo/Biosensing and Chemometrics, College of Chemistry and Chemical Engineering, Hunan University, Changsha 410082, Hunan, P. R. China.E-mail: ffxia@jsut.edu.cn; sunjh@jsut.edu.cn; hbyi@hnu.edu.cn

$\dagger$ F. Y. and F. X. contributed equally to this work.
}

effective structural doping approach to modify the photoelectrochemical properties of $\mathrm{g}-\mathrm{C}_{3} \mathrm{~N}_{4}$ by doping with nonmetal (sulfur or phosphorus) impurities, which reduced the energy gap to enhance the visible-light absorption of $\mathrm{g}-\mathrm{C}_{3} \mathrm{~N}_{4} \cdot{ }^{16} \mathrm{Lu}$ et al. reported that the photocatalytic efficiency of $\mathrm{g}-\mathrm{C}_{3} \mathrm{~N}_{4}$ can be enhanced by $\mathrm{H}$ ions plus $\mathrm{B}, \mathrm{N}, \mathrm{Si}, \mathrm{O}, \mathrm{P}$ and As ions with high coverage rates plus halogen ions with low coverage rates. ${ }^{17}$ Although much effort has been devoted to improving the photocatalytic activity of $\mathrm{g}-\mathrm{C}_{3} \mathrm{~N}_{4}$, it shows great necessity and urgency to discover new efficient approach to overcome the above mentioned problems and broaden the applications of $\mathrm{g}$ $\mathrm{C}_{3} \mathrm{~N}_{4}$ in water splitting and environmental pollutants degradation fields.

It has been reported that element doping is an efficient method to tune the unique electronic structure and band gap of $\mathrm{g}-\mathrm{C}_{3} \mathrm{~N}_{4}$, which considerably broadens the light responsive range and enhance the charge separation. ${ }^{16,17,20}$ However, the conventional doping with elemental impurities methods usually can introduce any bulk defects into the semiconductor lattice. In contrast, the surface charge transfer doping (SCTD) approach is nondestructive and does not induce any bulk defects into the semiconductor lattice, thus retaining the high performance of nanostructures by reducing carrier scattering in the bulk. ${ }^{33-35}$ In this approach, through controlling Fermi level 
$\left(E_{\mathrm{F}}\right)$ misalignment of surface dopants with respect to underlying semiconductor nanostructures, electrons can be extracted from (or injected into) the nanostructures, forming an electrondeficient (or electron-rich) surface layer. Carrier concentration and even conduction type of the semiconductor nanostructures can be readily tuned by varying the types as well as densities of surface dopants, leading to effective p-and n-type doping on the nanostructures. ${ }^{33-35}$ SCTD has been proven to be a simple, nondestructive, and effective method to tune both the electronic and optical properties of low-dimensional semiconductors, ${ }^{36-44}$ which is of fundamental importance to enable their wide applications in optoelectronic and electronic devices. For example, the electronic properties and carrier density of monolayer $\mathrm{MoS}_{2}$ monolayer could be effectively modulated with electron acceptor, tetracyanoquinodimethane (TCNQ), and electron donor, tetrathiafulvalene (TTF). ${ }^{41}$ Zhang et al. ${ }^{44}$ showed that phosphorene could be $\mathrm{p}$ - and n-type doped by modifying the surface with TCNQ and TTF, respectively. On the other hand, it was also reported that the optical properties of two dimensional (2D) materials could be modulated by SCTD. Jing et $a .^{41,43}$ disclosed that TCNQ and TTF could enhance the optical properties of $\mathrm{MoS}_{2}$ and phosphorene for effective light harvesting. All these reports suggested that SCTD is of fundamental importance to broaden their applications in optoelectronic and electronic devices. Although the SCTD scheme has been demonstrated to be very effective for $\mathrm{MoS}_{2}$ and phosphorene, so far there are few works that apply this method on the monolayer $\mathrm{g}-\mathrm{C}_{3} \mathrm{~N}_{4} \cdot{ }^{28,29}$

Herein, based on the density functional theory (DFT) with first-principles calculations, we demonstrated an efficient approach to improve the photocatalytic activity of monolayer g$\mathrm{C}_{3} \mathrm{~N}_{4}$ by SCTD using TCNQ and TTF as surface dopants. Our calculations revealed that TCNQ and TTF could act as acceptor and donor to inject holes and electrons into monolayer g- $\mathrm{C}_{3} \mathrm{~N}_{4}$, leading to electron-deficient and -rich surface layers, respectively. The remarkable surface charge transfer between the adsorbed molecules and the monolayers made TCNQ/TTF an efficient surface dopant to rationally tune the electronic and optical properties of monolayer $\mathrm{g}-\mathrm{C}_{3} \mathrm{~N}_{4}$. For TCNQ and TTF modified systems, the Fermi levels moves into the valence/ conduction band region, together with the increase/decrease of work functions, thus leading to $\mathrm{p}$-/n-type doping of monolayer $\mathrm{g}-\mathrm{C}_{3} \mathrm{~N}_{4}$. Moreover, the SCTD with TCNQ and TTF has also been found to be an effective way to enhance the light harvesting capabilities of the monolayer $\mathrm{g}-\mathrm{C}_{3} \mathrm{~N}_{4}$ in the visible-light region, which improves the photocatalytic activity and broadens the applications in splitting water and degrading environmental pollutants under sunlight irradiation.

\section{Computational methods}

All the first-principles calculations were performed using DFT based methods as implemented in the Cambridge Sequential Total Energy Package (CASTEP) program in Materials Studio 6.1 package of Accelrys Ltd. ${ }^{45-47}$ The Generalized Gradient Approximation (GGA) ${ }^{48}$ with the Perdew-Burke-Ernzerhof functional $(\mathrm{PBE})^{49,50}$ was adopted to describe the correction of the electronic exchange and correlation effects. Meanwhile, the van der Waals interactions between the monolayers and surface dopants (TCNQ and TTF) were described by the DFT-D2 method of Grimme. ${ }^{51}$ The interactions between valence electrons and ionic core were described by the Vanderbilt ultrasoft pseudopotential. ${ }^{52}$ The cutoff energy was set as $550 \mathrm{eV}$, and $8 \times 8 \times 1 \mathrm{k}$ points with the Monkhorst-Pack ${ }^{53}$ scheme in the first Brillouin zone was employed in the present work. Both the cutoff energy and $k$ grid were tested to be converged in the total energy. A slab of vacuum of $15 \AA$ in thickness in the $Z$ direction was applied to avoid the interaction with the image atoms. All of the structure models were fully relaxed, and the convergence criteria for geometric optimization and energy calculation were set to $2.0 \times 10^{-5} \mathrm{eV}$ per atom, $0.02 \mathrm{eV} \AA^{-1}, 0.005 \AA$ and $2.0 \times 10^{-6} \mathrm{eV}$ per atom for the tolerance of energy, maximum force, maximum ionic displacement, and self-consistent field (SCF), respectively.

In addition, the available adsorption sites of TCNQ and TTF on the surface of monolayer $\mathrm{g}-\mathrm{C}_{3} \mathrm{~N}_{4}$ were explored by comparing the adsorption energy $(\Delta E)$. And the $\Delta E$ was calculated according to the following definition:

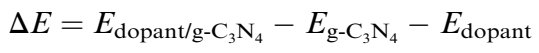

where $E_{\text {dopant/g- } \mathrm{C}_{3} \mathrm{~N}_{4}}, E_{\mathrm{g}_{-} \mathrm{C}_{3} \mathrm{~N}_{4}}$, and $E_{\text {dopant }}$ are the total energy of the surface modified system, intrinsic monolayer $\mathrm{g}-\mathrm{C}_{3} \mathrm{~N}_{4}$, and isolated dopant, respectively.

\section{Results and discussion}

To investigate the surface charge transfer doping effects on the monolayer $\mathrm{g}-\mathrm{C}_{3} \mathrm{~N}_{4}$, two typical p- and n-type organic surface dopants, including one electron-withdrawing molecule (TCNQ) and one electron-donating molecule (TTF), were chosen in this paper, as shown in Fig. 1a and b. And Fig. 1c also presents the top views of the energetically most favorable configuration of monolayer $\mathrm{g}-\mathrm{C}_{3} \mathrm{~N}_{4}$. For each molecule, we considered several possible adsorption sites and the energetically favorable configuration for these two molecules on the monolayer g- $\mathrm{C}_{3} \mathrm{~N}_{4}$ are presented in Fig. 2. And the possible adsorption sites of TCNQ and TTF on the surface of monolayer $\mathrm{g}-\mathrm{C}_{3} \mathrm{~N}_{4}$ were explored by comparing the adsorption energy $(\Delta E)$, which was

(a)

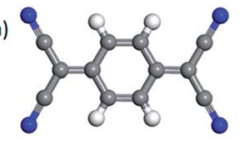

(b)

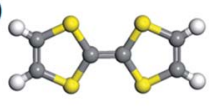

(c)

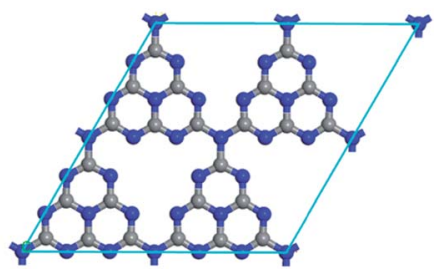

Fig. 1 The optimized energetically most favorable configurations for top views of (a) TCNQ, (b) TTF and (c) monolayer $\mathrm{g}-\mathrm{C}_{3} \mathrm{~N}_{4}$. 

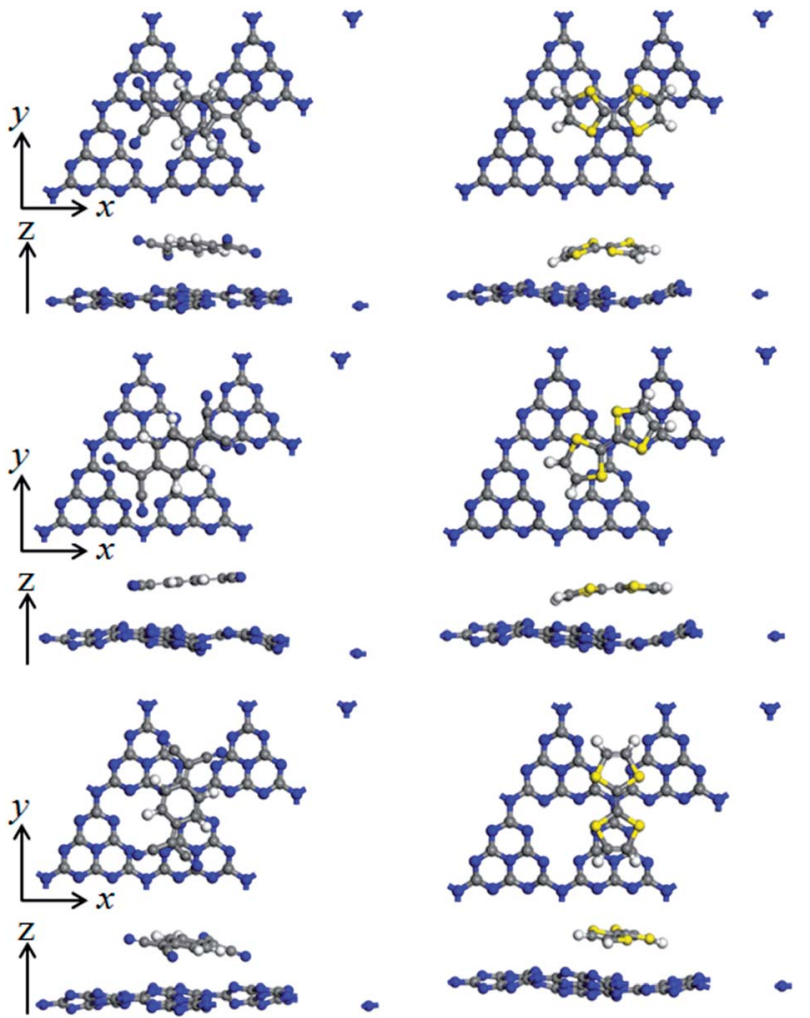

(a)

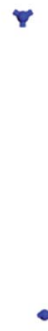

.

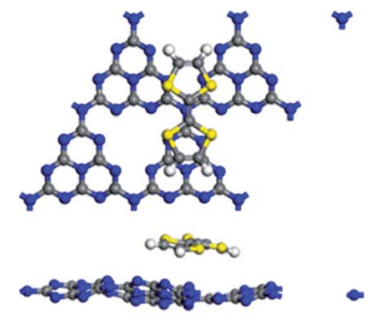

(b)
Fig. 2 Top and side views of TCNQ (a) and TTF (b) modified monolayer $\mathrm{g}-\mathrm{C}_{3} \mathrm{~N}_{4}$. Three adsorption positions on the surface of monolayer $\mathrm{g}$ $\mathrm{C}_{3} \mathrm{~N}_{4}$ are considered, and the adsorption positions along with $z$ axis are $0^{\circ}, 45^{\circ}$ and $90^{\circ}$ corresponding to the first line, second line and third line, respectively.

defined in the computational method section and a more negative $\Delta E$ indicated a more favorable configuration.

The electron-withdrawing/donating molecules, TCNQ and TTF, prefer adsorption on the basal surface of monolayer $\mathrm{g}-\mathrm{C}_{3} \mathrm{~N}_{4}$ along the $z$ direction with a vertical distance. And the adsorption energy of the three different configurations of TCNQ and TTF modified systems is $-0.12,-0.11,-0.12,-0.12,-0.12$ and $-0.12 \mathrm{eV}$ (Table 1), respectively, showing a non-covalent interaction between the surface dopants and monolayer g- $\mathrm{C}_{3} \mathrm{~N}_{4}$. It can be noted that the structure of monolayer $\mathrm{g}-\mathrm{C}_{3} \mathrm{~N}_{4}$ was

Table 1 Adsorption energy $(\Delta E)$, charge transfer $(q)$ and change of work function $(\Delta \Phi)^{a}$ of the TCNQ and TTF modified monolayer $\mathrm{g}-\mathrm{C}_{3} \mathrm{~N}_{4}$

\begin{tabular}{llllll}
\hline Geometries & Position & $\Delta E / \mathrm{eV}$ & $q_{\mathrm{ads}} / \mathrm{e}$ & $q_{\mathrm{g}^{-} \mathrm{C}_{3} \mathrm{~N}_{4}} / \mathrm{e}$ & $\Delta \Phi / \mathrm{eV}$ \\
\hline TCNQ modified g-C $\mathrm{C}_{3} \mathrm{~N}_{4}$ & $0^{\circ}$ & -0.12 & -0.12 & 0.12 & 1.21 \\
& $45^{\circ}$ & -0.11 & -0.10 & 0.10 & 1.20 \\
& $90^{\circ}$ & -0.12 & -0.11 & 0.11 & 1.19 \\
TTF modified g- $\mathrm{C}_{3} \mathrm{~N}_{4}$ & $0^{\circ}$ & -0.12 & 0.20 & -0.30 & -0.30 \\
& $45^{\circ}$ & -0.12 & 0.19 & -0.29 & -0.17 \\
& $90^{\circ}$ & -0.12 & 0.22 & -0.22 & -0.13
\end{tabular}

${ }^{a} \Delta \Phi$ is defined as $\Delta \Phi=\Phi_{\text {dopant } / \text { - }-\mathrm{C}_{3} \mathrm{~N}_{4}}-\Phi_{\mathrm{g}-\mathrm{C}_{3} \mathrm{~N}_{4}}$, where $\Phi_{\text {dopant } / \mathrm{g}-\mathrm{C}_{3} \mathrm{~N}_{4}}$ and $\Phi_{\mathrm{g}-\mathrm{C}_{3} \mathrm{~N}_{4}}$ are the work functions of the surface modified system and the intrinsic monolayer g- $\mathrm{C}_{3} \mathrm{~N}_{4}$, respectively. obviously bending after TCNQ and TTF surface modification due to the non-covalent interaction between the surface dopants and monolayer $g-\mathrm{C}_{3} \mathrm{~N}_{4}$. In addition, Mulliken charge analysis of bond population ${ }^{54,55}$ for the TCNQ modified systems show that there are about -0.11 charge transfers from the monolayer $\mathrm{g}-\mathrm{C}_{3} \mathrm{~N}_{4}$ to TCNQ, revealing that the TCNQ molecule can act as a strong acceptor on the surface of monolayer g- $\mathrm{C}_{3} \mathrm{~N}_{4}$. In contrast, for the TTF modified monolayer $\mathrm{g}-\mathrm{C}_{3} \mathrm{~N}_{4}$ systems, TTF acts as a donor and injects electrons into the monolayers (as shown in Table 1). As a result, the adsorption of TCNQ and TTF lead to positively and negatively charged monolayer g- $\mathrm{C}_{3} \mathrm{~N}_{4}$, manifesting that surface modification by TCNQ and TTF molecules could be an effective approach to modulate the carrier concentrations in g- $\mathrm{C}_{3} \mathrm{~N}_{4}$ monolayers.

To explore the work function variations of monolayer g- $\mathrm{C}_{3} \mathrm{~N}_{4}$ before and after surface modification, the electrostatic potential calculations were further performed to study the changes of work functions $\left(\Delta \Phi=\Phi_{\text {dopant } / g-\mathrm{C}_{3} \mathrm{~N}_{4}}-\Phi_{\mathrm{g}_{-} \mathrm{C}_{3} \mathrm{~N}_{4}}\right)$ for monolayer $\mathrm{g}$ $\mathrm{C}_{3} \mathrm{~N}_{4}$ after surface modifications. As shown in Table 1, there is an obvious increase of work functions for monolayer $\mathrm{g}-\mathrm{C}_{3} \mathrm{~N}_{4}$ by $1.21,1.20$, and $1.19 \mathrm{eV}$, respectively, after the adsorption of TCNQ, attributing to the injection of holes from TCNQ into the monolayers. In contrast, due to the injection of electrons from TTF molecule, the adsorption of TTF results in a decrease of work function by $0.30,0.17$, and $0.13 \mathrm{eV}$, respectively. It can be also noted that the work function of TCNQ modified monolayer $\mathrm{g}^{-} \mathrm{C}_{3} \mathrm{~N}_{4}$ is higher than that of intrinsic monolayers, while the work function of TTF modified monolayer $\mathrm{g}_{-} \mathrm{C}_{3} \mathrm{~N}_{4}$ is lower than that of intrinsic monolayers (shown in Fig. 3), in accordance with the literature reports. ${ }^{40,56}$ These phenomena indicate that the monolayer $\mathrm{g}-\mathrm{C}_{3} \mathrm{~N}_{4}$ may be tuned into $\mathrm{p} / \mathrm{n}$-type materials by doping with the electron-withdrawing/donating TCNQ and TTF molecules.

To examine whether the surface dopants (TCNQ and TTF) have an effect on electronic properties of the monolayer g- $\mathrm{C}_{3} \mathrm{~N}_{4}$ due to charge transfer between surface dopants (TCNQ and TTF) and monolayer $g-\mathrm{C}_{3} \mathrm{~N}_{4}$, the electronic band structures of monolayer $\mathrm{g}-\mathrm{C}_{3} \mathrm{~N}_{4}$ before and after surface modification were computed (Fig. 4). Fig. 4a-c presents the electronic band structures of the intrinsic and surface modified monolayer g- $\mathrm{C}_{3} \mathrm{~N}_{4}$, respectively. Remarkably, the intrinsic monolayer g- $\mathrm{C}_{3} \mathrm{~N}_{4}$ is an indirect-gap semiconductor with a bandgap of $1.15 \mathrm{eV}$ at GGA/PBE level, while with a bandgap of $2.70 \mathrm{eV}$ at

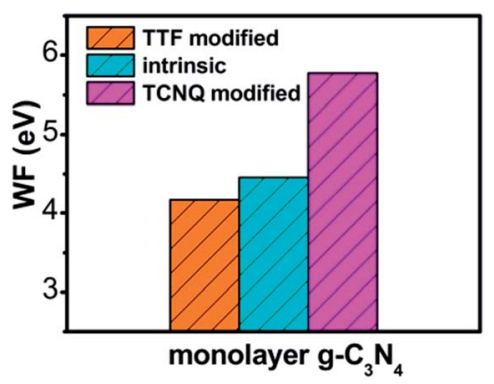

Fig. 3 The plot of calculated work function of intrinsic and different organic molecules modified monolayer $\mathrm{g}-\mathrm{C}_{3} \mathrm{~N}_{4}$ at GGA/PBE level. 


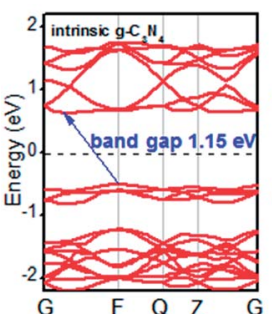

(a)

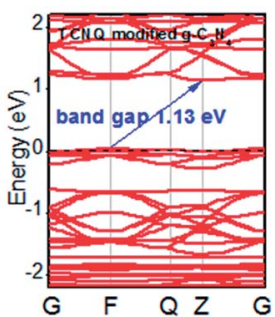

(b)

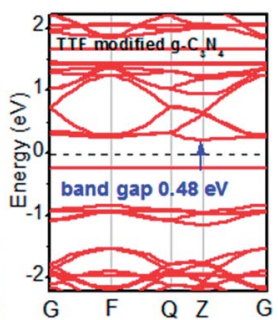

(c)
Fig. 4 Band structures of (a) intrinsic, (b) TCNQ and (c) TTF modified monolayer $\mathrm{g}-\mathrm{C}_{3} \mathrm{~N}_{4}$ at GGA/PBE level. The dashed lines indicate the $E_{\mathrm{F}}$.

HSE06 level, which agrees well with previous reports. ${ }^{24,57}$ For TCNQ modified system, it can be noted that the Fermi level $\left(E_{\mathrm{F}}\right)$ moves into the valence band region that probably attributed to the adsorption of TCNQ molecule. And the shift of original $E_{\mathrm{F}}$ in monolayer $g-\mathrm{C}_{3} \mathrm{~N}_{4}$ to the lower energy regions leads to the increase of work function. These phenomena reveal that monolayer $\mathrm{g}^{-} \mathrm{C}_{3} \mathrm{~N}_{4}$ can be p-type doped with TCNQ surface modification. In contrast, for TTF modified system, there appears a new flat energy level below the Fermi level that mainly attributed to the TTF molecule. The appearance of the new empty flat band in the bandgaps shifts the original $E_{\mathrm{F}}$ in the monolayer $\mathrm{g}^{-} \mathrm{C}_{3} \mathrm{~N}_{4}$ to the higher energy region, thus decreases the work functions. The new flat level can act as a donor state in TTF-modified system, which is in favor of the charge transfer from TTF to monolayer $\mathrm{g}_{-} \mathrm{C}_{3} \mathrm{~N}_{4}$. In the meantime, the new flat band below the Fermi level is close to the conduction band minimum (CBM) in the TTF modified system (Fig. 4c), verifying that it acts as a donor state for n-type doping. The density of states (DOS) of the molecule-modified systems and the projected density of states (PDOS) for both the adsorbed molecules and monolayer $g-\mathrm{C}_{3} \mathrm{~N}_{4}$ in these adsorption systems were also computed (Fig. 5), which validate the results from the band structures and confirm that the new flat energy levels were generated by the absorbed molecule. The above results collectively demonstrate that TCNQ and TTF can p- and n-type doping of monolayer g- $\mathrm{C}_{3} \mathrm{~N}_{4}$, respectively.

It can be noted that the charge transfer between the surface dopants (TCNQ and TTF) and monolayer $\mathrm{g}^{-} \mathrm{C}_{3} \mathrm{~N}_{4}$ have an obvious effects on the electronic properties of monolayer $\mathrm{g}-\mathrm{C}_{3} \mathrm{~N}_{4}$. Therefore, the electron density difference $(\Delta \rho)$ of monolayer $\mathrm{g}-\mathrm{C}_{3} \mathrm{~N}_{4}$ before and after TCNQ and TTF modification

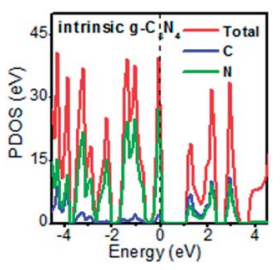

(a)

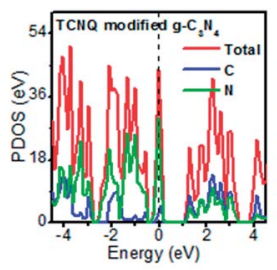

(b)

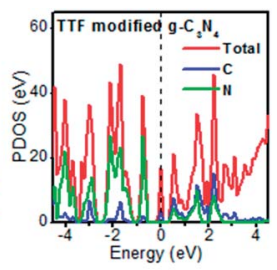

(c)
Fig. 5 The projected density of states (PDOS) of the (a) intrinsic, (b) TCNQ and (c) TTF modified monolayer $\mathrm{g}-\mathrm{C}_{3} \mathrm{~N}_{4}$ at GGA/PBE level. The dashed lines indicate the $E_{\mathrm{F}}$. was calculated to visualize the charge transfer between the surface dopants (TCNQ and TTF) and monolayer g- $\mathrm{C}_{3} \mathrm{~N}_{4}$ (Fig. 6). $\Delta \rho$ illustrates how the electron density changes during the adsorption process and is defined as $\Delta \rho=\rho_{\text {dopant } / g-\mathrm{C}_{3} \mathrm{~N}_{4}}-\rho_{\text {dopant }}$ $-\rho_{\mathrm{g}-\mathrm{C}_{3} \mathrm{~N}_{4}}$, in which $\rho_{\text {dopant } / \mathrm{g}-\mathrm{C}_{3} \mathrm{~N}_{4}}, \rho_{\text {dopant }}$, and $\rho_{\mathrm{g}-\mathrm{C}_{3} \mathrm{~N}_{4}}$ denote the electron density of the surface modified system, the isolated molecule and the isolated monolayer $\mathrm{g}-\mathrm{C}_{3} \mathrm{~N}_{4}$, respectively. Fig. $6 \mathrm{a}$ and $\mathrm{b}$ show the change of electron density in the monolayer $\mathrm{g}_{-} \mathrm{C}_{3} \mathrm{~N}_{4}$ after TCNQ and TTF surface modification, where the gain and loss of electrons is presented in red and blue color, respectively. For TCNQ modified system, there are obvious electrons depletion on the surface of monolayer g- $\mathrm{C}_{3} \mathrm{~N}_{4}$, while strong electrons accumulation around TCNQ molecule. In contrast, for TTF modified system, the adsorption of TTF leads to the electrons enrichment on the surface of monolayer g- $\mathrm{C}_{3} \mathrm{~N}_{4}$ and the electrons depletion around TTF molecule. These phenomena intuitively reveal that TCNQ and TTF can draw and donate electrons from/to monolayer $g-\mathrm{C}_{3} \mathrm{~N}_{4}$ as acceptor and donor, respectively, and these results are consistent with the Mulliken charge transfer analysis in Table 1. In addition, both electrons accumulation and depletion appear on the surface of monolayer $\mathrm{g}^{-} \mathrm{C}_{3} \mathrm{~N}_{4}$, suggesting there are charge transfers both between intramolecules and intermolecules.

The electronic properties of monolayer $\mathrm{g}^{-} \mathrm{C}_{3} \mathrm{~N}_{4}$ can be tuned by the TCNQ and TTF surface modification, and to explore surface modification with TCNQ and TTF whether can improve the optical properties of monolayer g- $\mathrm{C}_{3} \mathrm{~N}_{4}$, the optical spectra of the intrinsic and surface-modified monolayer g- $\mathrm{C}_{3} \mathrm{~N}_{4}$ were calculated (Fig. 7). The imaginary part of the dielectric functions $\left(\varepsilon_{2}\right)$ is an effective parameter to measure the optical absorption ability of materials, and the peaks in $\varepsilon_{2}$ are caused by the absorption of incident photons and the interband transition of

(a)

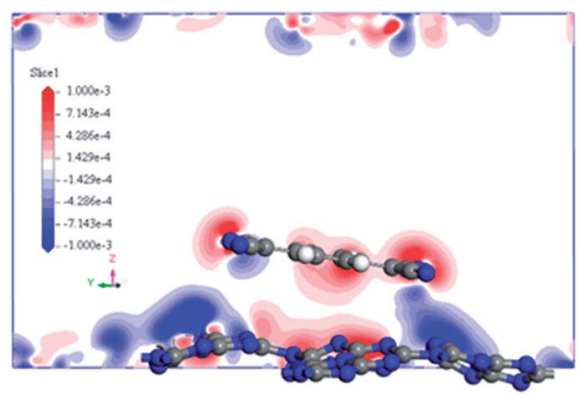

(b)

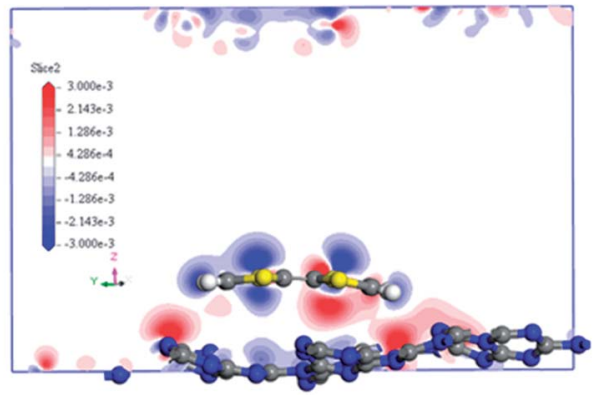

Fig. 6 The difference electron density of (a) TCNQ and (b) TTF modified monolayer $\mathrm{g}-\mathrm{C}_{3} \mathrm{~N}_{4}$. A loss of electrons is indicated in blue, while electron enrichment in red. 


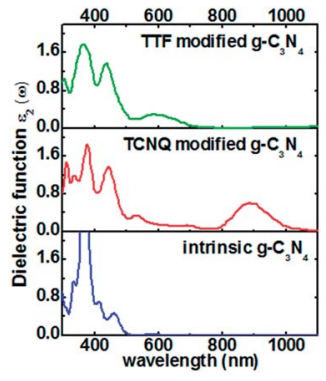

Fig. 7 Computed imaginary dielectric functions versus wavelength for intrinsic (blue lines), TCNQ (red lines) and TTF (green lines) modified monolayer $\mathrm{g}-\mathrm{C}_{3} \mathrm{~N}_{4}$

electrons. ${ }^{58,59}$ As shown in Fig. 7, there is an appreciable largest absorption peak around $460 \mathrm{~nm}$ for intrinsic monolayer $\mathrm{g}-\mathrm{C}_{3} \mathrm{~N}_{4}$ (blue curve in Fig. 7), which is in good agreement with previous report ${ }^{16}$ and denotes the monolayer $\mathrm{g}-\mathrm{C}_{3} \mathrm{~N}_{4}$ is a visible-light semiconductor material. However, the absorption intensity of monolayer $\mathrm{g}-\mathrm{C}_{3} \mathrm{~N}_{4}$ is weak in the visible-light region, which is not enough to contribute to the highly photocatalytic activity of $\mathrm{g}^{-} \mathrm{C}_{3} \mathrm{~N}_{4}$. For TCNQ modified system, new absorption peaks appear in the region of $530-880 \mathrm{~nm}$, and the absorption intensity of peak around $880 \mathrm{~nm}$ is increased compared to that of intrinsic monolayer $\mathrm{g}-\mathrm{C}_{3} \mathrm{~N}_{4}$ peak around $460 \mathrm{~nm}$. These new peaks round $530-880 \mathrm{~nm}$ could contribute to improve the photocatalytic activity of monolayer $\mathrm{g}-\mathrm{C}_{3} \mathrm{~N}_{4}$. Similar to TTF modified system, it can be noted that a new visible-light absorption peak appears around $586 \mathrm{~nm}$, which can also contribute to improve the photocatalytic activity of monolayer $\mathrm{g}^{-} \mathrm{C}_{3} \mathrm{~N}_{4}$. All these phenomena suggest that both TCNQ and TTF surface modification can induce an increase of optical absorption range and the absorption intensity in the visible-light region of monolayer $\mathrm{g}-\mathrm{C}_{3} \mathrm{~N}_{4}$. This will be of great importance to improve the photocatalytic activity of monolayer $\mathrm{g}-\mathrm{C}_{3} \mathrm{~N}_{4}$ and broaden its applications in splitting water and degrading environmental pollutants under sunlight irradiation.

\section{Conclusions}

In conclusion, we have proposed an efficient approach to improve the photocatalytic activity of monolayer $\mathrm{g}-\mathrm{C}_{3} \mathrm{~N}_{4}$ via surface charge transfer doping with TCNQ and TTF molecules. The electronic and optical properties of intrinsic and surface modified monolayer $\mathrm{g}-\mathrm{C}_{3} \mathrm{~N}_{4}$ were systematically investigated by means of DFT computations. It was found that TCNQ could act as an acceptor to draw electrons from the monolayer $g-\mathrm{C}_{3} \mathrm{~N}_{4}$, leading to pronounced holes accumulation in the monolayers and increased work functions. While TTF could act as a donor to inject electrons into the monolayer $\mathrm{g}-\mathrm{C}_{3} \mathrm{~N}_{4}$, resulting in the accumulation of electrons on the monolayers and decreased work functions. The remarkable surface charge transfer between the adsorbed molecules and the monolayers made TCNQ/TTF an efficient surface dopant to rationally tune the electronic properties of monolayer $\mathrm{g}-\mathrm{C}_{3} \mathrm{~N}_{4}$. Moreover, the adsorptions of TCNQ and TTF on monolayer $\mathrm{g}-\mathrm{C}_{3} \mathrm{~N}_{4}$ could induce an increase of optical absorption range and the absorption intensity in the visible-light region, improving the photocatalytic activity of monolayer $\mathrm{g}-\mathrm{C}_{3} \mathrm{~N}_{4}$. Our work demonstrates the great potential of SCTD method on the rational tuning of the electronic and optical properties of monolayer $\mathrm{g}$ $\mathrm{C}_{3} \mathrm{~N}_{4}$, opening up the opportunities to improve the photocatalytic activity of monolayer $g-\mathrm{C}_{3} \mathrm{~N}_{4}$ via SCTD.

\section{Conflicts of interest}

There are no conflicts to declare.

\section{Acknowledgements}

This work was supported by the National Natural Science Foundation of China (No. 21703087, 21406020, 21373103) and the Natural Science Foundation of Jiangsu Province (No. BK20140257). We acknowledge the computing resources and technical support from National Super Computing Center in Shenzhen (Shenzhen Cloud Computing Center).

\section{Notes and references}

1 X. Wang, K. Maeda, A. Thomas, K. Takanabe, G. Xin, J. M. Carlsson, K. Domen and M. Antonietti, Nat. Mater., 2009, 8, 76-80.

2 G. Zhang, J. Zhang, M. Zhang and X. J. Wang, Mater. Chem., 2012, 22, 8083-8091.

3 K. Wang, Q. Li, B. Liu, B. Cheng, W. Ho and J. Yu, Appl. Catal., B, 2015, 176, 44-52.

4 Q. Huang, J. Yu, S. Cao, C. Cui and B. Cheng, Appl. Surf. Sci., 2015, 358, 350-355.

5 S. C. Yan, Z. S. Li and Z. G. Zou, Langmuir, 2009, 25, 1039710401.

6 S. C. Yan, Z. S. Li and Z. G. Zou, Langmuir, 2010, 26, 38943901.

7 J. Zhu, P. Xiao, H. Li and S. A. S. Carabineiro, ACS Appl. Mater. Interfaces, 2014, 6, 16449-16465.

8 J. H. Sun, J. S. Zhang, M. W. Zhang, M. Antonietti, X. Z. Fu and X. X. Wang, Nat. Commun., 2012, 3, 1139.

9 H. Ou, L. Lin, Y. Zheng, P. Yang, Y. Fang and X. Wang, Adv. Mater., 2017, 29, 1700008.

10 P. Yang, H. Ou, Y. Fang and X. Wang, Angew. Chem., Int. Ed., 2017, 56, 3992-3996.

11 W. J. Ong, L. L. Tan, Y. H. Ng, S. T. Yong and S. P. Chai, Chem. Rev., 2016, 116, 7159-7329.

12 X. B. Chen, S. H. Shen, L. J. Guo and S. S. Mao, Chem. Rev., 2010, 110, 6503-6570.

13 A. Kudo and Y. Miseki, Chem. Soc. Rev., 2009, 38, 253-278.

14 H. Zhang, F. Liu, Z. G. Mou, X. F. Liu, J. H. Sun and W. W. Lei, Chem. Commun., 2016, 52, 13020-13023.

15 H. Zhang, F. Liu, H. Wu, X. Cao, J. H. Sun and W. W. Lei, RSC Adv., 2017, 7, 40327-40333.

16 X. G. Ma, Y. H. Lv, J. Xu, Y. F. Liu, R. Q. Zhang and Y. F. Zhu, J. Phys. Chem. C, 2012, 116, 23485-23493. 
17 S. Lu, Z. W. Chen, C. Li, H. H. Li, Y. F. Zhao, Y. Y. Gong, L. Y. Niu, X. J. Liu, T. Wang and C. Q. Sun, J. Mater. Chem. A, 2016, 4, 14827-14838.

18 Z. Y. Mao, J. J. Chen, Y. F. Yang, L. J. Bie, B. D. Fahlman and D. J. Wang, Carbon, 2017, 123, 651-659.

19 L. B. Jiang, X. Z. Yuan, Y. Pan, J. Liang, G. M. Zeng, Z. B. Wu and H. Wang, Appl. Catal., B, 2017, 217, 388-406.

20 L. Zhou, H. Y. Zhang, H. Q. Sun, S. M. Liu, M. O. Tade, S. B. Wang and W. Q. Jin, Catal. Sci. Technol., 2016, 6, 7002-7023.

21 K. N. Ding, L. L. Wen, M. Y. Huang, Y. F. Zhang, Y. P. Lu and Z. F. Chen, Phys. Chem. Chem. Phys., 2016, 18, 19217-19226.

22 K. Srinivasu, B. Modak and S. K. Ghosh, Phys. Chem. Chem. Phys., 2016, 18, 26466-26474.

23 K. Srinivasu and S. K. Ghosh, J. Mater. Chem. A, 2015, 3, 23011-23016.

24 B. C. Zhu, J. F. Zhang, C. J. Jiang, B. Cheng and J. G. Yu, Appl. Catal., B, 2017, 207, 27-34.

25 S. Stolbov and S. Zuluaga, J. Phys.: Condens. Matter, 2013, 25, 085507.

26 J. J. Liu, J. Alloys Compd., 2016, 672, 271-276.

27 S. Lu, C. Li, H. H. Li, Y. F. Zhao, Y. Y. Gong, L. Y. Niu, X. J. Liu and T. Wang, Appl. Surf. Sci., 2017, 392, 966-974.

28 S. M. Aspera, M. David and H. Kasai, Jpn. J. Appl. Phys., 2010, 49, 115703.

29 B. C. Zhu, L. Y. Zhang, D. F. Xu, C. Cheng and J. G. Yu, J. CO2 Util., 2017, 21, 327-335.

30 J. Y. Li, W. Cui, Y. J. Sun, Y. H. Chu, W. L. Cen and F. Dong, J. Mater. Chem. A, 2017, 5, 9358-9364.

31 W. Cui, J. Y. Li, F. Dong, Y. J. Sun, G. M. Jiang, W. L. Cen, S. C. Lee and Z. B. Wu, Environ. Sci. Technol., 2017, 51, 10682-10690.

32 W. Cui, J. Y. Li, W. L. Cen, Y. J. Sun, S. C. Lee and F. Dong, J. Catal., 2017, 352, 351-360.

33 J. Ristein, Science, 2006, 313, 1057-1058.

34 W. Chen, D. C. Qi, X. Y. Gao and A. T. S. Wee, Prog. Surf. Sci., 2009, 84, 279-321.

35 H. Lüth, Solid Surfaces, Interfaces and Thin Films, SpringerVerlag, New York, 2001.

36 F. F. Xia, Z. B. Shao, Y. Y. He, R. B. Wang, X. F. Wu, T. H. Jiang, S. Duhm, J. W. Zhao, S. T. Lee and J. S. Jie, ACS Nano, 2016, 10, 10283-10293.

37 F. F. Xia, S. Y. Xiong, Y. Y. He, Z. B. Shao, X. J. Zhang and J. S. Jie, J. Phys. Chem. C, 2017, 121, 19530-19537.
38 W. Chen, S. Chen, D. C. Qi, X. Y. Gao and S. T. S. Wee, J. Am. Chem. Soc., 2007, 129, 10418-10422.

39 T. Hu and I. C. Gerber, J. Phys. Chem. C, 2013, 117, 24112420.

40 Y. Q. Cai, H. B. Zhou, G. Zhang and Y. W. Zhang, Chem. Mater., 2016, 28, 8611-8621.

41 Y. Jing, X. Tan, Z. Zhou and P. W. Shen, J. Mater. Chem. A, 2014, 2, 16892-16897.

42 Y. Y. He, F. F. Xia, Z. B. Shao, J. W. Zhao and J. S. Jie, J. Phys. Chem. Lett., 2015, 6, 4701-4710.

43 Y. Jing, Q. Tang, P. He, Z. Zhou and P. Shen, Nanotechnology, 2015, 26, 095201.

44 R. Zhang, B. Li and J. Yang, J. Phys. Chem. C, 2015, 119, 28712878.

45 P. Hohenberg and W. Kohn, Phys. Rev. B, 1964, 136, B864B871.

46 W. Kohn and L. Sham, Phys. Rev., 1965, 140, A1133-A1138.

47 S. J. Clark, M. D. Segall, C. J. Pickard, P. J Hasnip, M. I. J. Probert, K. Refson and M. C. Payne, Z. Kristallogr. $B, 2005,220,567-570$.

48 A. Zupan, K. Burke, M. Ernzerhof and J. P. Perdew, J. Chem. Phys., 1997, 106, 10184-10193.

49 J. P. Perdew, K. Burke and M. Ernzerhof, Phys. Rev. Lett., 1996, 77, 3865-3868.

50 J. Perdew and Y. Wang, Phys. Rev. B, 1992, 45, 13244-13249.

51 S. Grimme, J. Comput. Chem., 2006, 27, 1787-1799.

52 D. Vanderbilt, Phys. Rev. B, 1990, 41, 7892-7895.

53 H. J. Monkhorst and J. D. Pack, Phys. Rev. B, 1976, 13, 51885192.

54 M. D. Segall, C. J. Pickard, R. Shah and M. C. Payne, Mol. Phys., 1996, 89, 571-577.

55 M. D. Segall, R. Shah, C. J. Pickard and M. C. Payne, Phys. Rev. B, 1996, 54, 16317-16320.

56 R. C. Selhorst, E. Puodziukynaite, J. A. Dewey, P. J. Wang, M. D. Barnes, A. Ramasubramaniamc and T. Emrick, Chem. Sci., 2016, 7, 4698-4705.

57 S. P. Sun, S. Gu, J. H. Sun, F. F. Xia and G. H. Chen, J. Alloys Compd., 2018, 735, 131-139.

58 M. Gajdos, K. Hummer, G. Kresse, J. Furthmuller and F. Bechstedt, Phys. Rev. B, 2006, 73, 045112.

59 C. Ambrosch-Draxl and J. O. Sofo, Comput. Phys. Commun., 2006, 175, 1-14. 